\section{Cantores palaciegos: Un estudio sobre la figura del aedo en la Odisea*}

\section{Palatial Singers:}

A Study on the Figure of the Aoidos in the Odyssey

\section{Cantores \\ Palacianos: \\ Um estudo sobre a \\ figura do aedo na \\ Odisseia}

Segundo semestre de 2019 - pp. 83-96

Segunda época

N.
Mauricio Vélez Upegui** ORCID: https://orcid.org/0000-0002-9359-7429

* Este trabajo es resultado parcial de la investigación titulada " ¿Lo trágico en Homero?", iniciada en enero de 2016 y desarrollada en el grupo de investigación "Estudios en filosofía, hermenéutica y narrativas" (categoría A1 de Colciencias) del Departamento de Humanidades de la Universidad EAFIT.

** Magíster en literatura colombiana de la Universidad de Antioquia. Actualmente, Profesor Asistente del Departamento de Humanidades de la Universidad EAFIT. Correo electrónico: mavelez@eafit.edu.co
Vélez, M. (2019). Cantores palaciegos: Un estudio sobre la figura del aedo en la Odisea. Folios, 50, 83-96. doi: 10.17227/Folios.50-7457
Artículo recibido $23 \cdot 01 \cdot 2018$

Artículo aprobado $25 \cdot 01 \cdot 2019$ 


\section{Resumen}

En este texto, producto parcial de la investigación en curso titulada “¿Lo trágico en Homero?”, me propongo caracterizar, desde una perspectiva poético-cultural, la figura del aedo en Homero, tal como su rol épico aparece referido y descrito en la Odisea. La premisa de la cual parto, y que opera al mismo tiempo como conjetura de trabajo, es la siguiente: el aedo es un funcionario de palacio que, en lugar de prestar un simple servicio doméstico, entona ciertos relatos cuyo contenido tiende a reforzar un orden social determinado ante auditorios compuestos por individuos pertenecientes a la clase señorial. Dado que tres son las partes que subyacen a la conjetura, tres son los apartados en que el estudio se distribuye: a) establecimiento de las similitudes y diferencias entre los cuatro aedos que son mencionados en el texto; b) esclarecimiento de la función cantora de los aedos atendiendo al medio, modo e instrumento de ejecución de los cantos; y c) comparación temática de los tipos de canto ejecutados, así como de las reacciones de sus distintos auditorios. Al final, concluimos afirmando que el aedo, al interpretar cantos que remiten bien a prácticas rituales, bien a leyendas divinas y heroicas, funge de intermediario en una sociedad jerárquicamente dividida, en la que gentes del común y nobles guerreros 0 viajeros coexisten de modo complementario.

Palabras clave

Homero; Odisea; aedo; canciones; auditorio

Abstract

In this text, partial product of the ongoing research Tragic in Homer? I propose to describe, from a poetical and cultural perspective, the figure of aoidos in Homer, such as its epic role appears in the Odyssey. The premise from which I start and which serves as conjecture for this work is the following: Aoidos is a palace servant who, instead of providing a simple domestic service, sings certain accounts whose content tends to reinforce a determined social order before audiences composed by individuals form the stately class. Given that the conjecture has three parts, three are the sections to distribute this study: a) establishment of similarities and differences between the four aoidos in the text; b) clarification of the singing function of aoidos according to means, manner and instrument of execution c) theme comparison of types of songs as well as the reactions from the different audiences. We finally conclude that when aoidos performs songs that refer to ritual practices, divine or heroic legends, serve as intermediary in a hierarchy divided society in which regular people and noble warriors or travelers cohabitate in a complementary way.

\section{Keywords}

Homer; Odyssey, aoidos; songs; audience

\section{Resumo}

Neste texto, parcial da investigação em curso intitulado "A tragédia em Homer?", proponho caracterizar, do ponto de vista poético-cultural, a figura do aedo em Homer, como seu papel épico aparece mencionado e descrito em Odisséia. A premissa inicial, que opera ao mesmo tempo que uma conjectura de trabalho, é a seguinte: o aedo é um funcionário do palácio que, em vez de prestar um serviço doméstico simples, entoa certas histórias cujo conteúdo tende a reforçar uma certa ordem social diante de auditórios compostos de indivíduos pertencentes à classe senhorial. Como três são as partes que fundamentam a conjectura, três são as seções nas quais o estudo é distribuído: a) estabelecimento das semelhanças e diferenças entre os quatro aedos mencionados no texto; b) esclarecimento da função cantora dos aedos atendendo ao médium, modo e instrumento de execução das canções e c) comparação temática dos tipos de músicas executadas, bem como as reações de seus diferentes públicos. No final, podemos concluir afirmando que o aedo quando interpreta canções que se referem bem a práticas rituais, ou a lendas divinas e heróicas, ele atua como intermediário em uma sociedade hierarquicamente dividida, na qual pessoas comuns e nobres guerreiros ou viajantes coexistem de maneira complementar.

Palavras-chave

Homer; Odisséia; aedo músicas; auditório 


\section{Introducción}

Quien, como lector de Homero, abandona las páginas dedicadas a narrar la brutal, sanguinaria y nefasta lucha entre aqueos y troyanos descrita en la Ilíada y opta por acompañar a Odiseo en su viaje de regreso a Ítaca, acaba por comprender que uno de los rasgos distintivos del género épico, en cuanto producción del espíritu que surge como resultado de una larga tradición prealfabética, es la numerosidad de personajes. En lo que atañe a la Odisea, poema probablemente compuesto un par de generaciones después de que los griegos conocieran el florecimiento de Hesíodo (Finley, 2014 [1954], p. 39), el número de seres que cumple una función diegética menor o mayor, según cómputos discretos, asciende a más de 350 (Ramos, 1988, p. 34). Tal cifra sirve para englobar tanto a agentes colectivos -caso de los más de cien varones que pretenden a Penélope durante la ausencia del soberano de Ítaca-, como a figuras diestramente retocadas -caso del porquero Eumeo o de Euriclea, la nodriza-. Unos y otros, en momentos diferentes de la intriga, traban contacto entre sí, no sin ensanchar el tejido dramático de las situaciones representadas, y conducen la acción hacia un desenlace, si no necesario, verosímil.

Pero Homero, a quien Aristóteles no cesa de elogiar (Poética, 8, 1451a, 24; 17, 1455b, 15-20; 23, 1459a, 30-31), no impregna su discurso únicamente de datos cuantitativos; para él, asimismo, es importante proveer de cualidades a aquellos personajes que son objeto de identificación y referencia. Dejando aparte animales tan entrañables como el perro Argos o monstruos tan pavorosos como Escila y Caribdis, tres son los tipos de personajes que pueblan el mundo relatado por la Odisea: dioses, héroes y simples seres humanos. Dichos tipos, al tiempo que realizan innumerables acciones acordes con su respectiva naturaleza, se muestran divididos socialmente según una explícita gradación o jerarquía. Homero sitúa a los dioses en el Olimpo, esto es, en una región topológicamente superior respecto de la Tierra. Imaginados con rasgos antropomórficos, los dioses son "lo sagrado por excelencia, en el sentido de lo radicalmente otro del ser humano" (Castoriadis,
2006, p. 157). Eso otro radicalmente diferente dimana del poder sobrehumano que tanto los mitos como los ritos les reconocen (Vernant, 1991 [1990], p. 23). En Homero, además, los dioses no pierden ocasión para inmiscuirse en los asuntos humanos, $y$, en particular, en las empresas de aquellos que encarnan el poder: reyes o soberanos. Ocupando una posición intermedia entre los dioses y los mortales ordinarios, los reyes pertenecen a la clase de los mejores (aristoi). Su supremacía está dada por una serie de atributos cuyo contenido se sintetiza en una palabra de hondas repercusiones, arete, vale anotar, fuerza física y vigor corporal a la vez que agudeza e ingenio espiritual (Finkelberg, 1998, p. 20; Jaeger, 1967, p. 22; Long, 1970, p. 129). El ámbito de acción donde los reyes ponen a prueba su excelencia no es otro que el campo de batalla, y ello explica por qué, en la Odisea, la mayoría de los reyes son héroes que han participado en la guerra contra Troya. Pero la soberanía heroica pasa por una validación adicional, ligada con el concepto de riqueza. Más que ponderarse por la moneda, la riqueza se tasa por los bienes tenidos y conseguidos: mantos, armas, objetos suntuarios, ganado y personas (Adkins, 1972, p. 4). Son estas las que conforman la tercera escala social. Llámense esclavos, despenseras, escanciadores, boyeros, pastores, todos conforman un entramado humano que, a cambio de su fuerza de trabajo, reciben cobijo y sustento material en el seno de las casas señoriales.

De entre los muchos personajes que intervienen en la Odisea para dotar de interés humano el dilatado y peligroso retorno del héroe epónimo, hay uno en particular que goza de características especiales y que se destaca por el rol desempeñado en la trama épica: aedo es el nombre con que Homero se refiere a él. Ocuparnos de este personaje en el poema mencionado es el propósito que anima a este escrito. En lo que sigue, nos interesa realizar una semblanza de su rol épico. Para caracterizar dicha semblanza, formularemos una conjetura interpretativa que elaboramos a partir del poema mismo, y no de fuentes extratextuales: el aedo es un funcionario de palacio que, en lugar de prestar un simple servicio doméstico -del tipo servir el vino, trinchar la carne o arreglar las habitaciones para el 
huésped-, entona ciertos relatos cuyo contenido tiende a reforzar un orden social determinado ante auditorios compuestos por individuos pertenecientes a la clase señorial. Así, entonces, partiremos la conjetura en tres segmentos y procederemos a su desarrollo. Dedicaremos el primer segmento a precisar elementos propios de la identidad de los aedos que son mencionados en el poema, intentando mostrar sus diferencias y semejanzas; destinaremos el segundo a explicitar la función cantora del aedo, indicando las particularidades de esta (medio, modo e instrumento); $y$, en el tercero, agruparemos los cantos en clases específicas y detallaremos las respuestas emotivas de los diversos auditorios ante ellos. Quizá no sobre acotar que trabajaremos la conjetura de dos maneras, analítico-descriptiva, una, es decir, estableciendo unidades y relaciones textuales entre distintos pasajes del poema, e interpretativa, la otra, esto es, formulando líneas de significación que subyacen a las unidades y relaciones consideradas.

\section{Segmentación de la conjetura}

\section{¿Qué cabe apuntar sobre la}

identidad del aedo?

De entrada, permítasenos hacer una precisión etimológica. El aedo (aoidos) debe su nombre a la actividad especializada que realiza, a saber: cantar (aoidein) (Chantraine, 1968, pp. 21-22; Liddell y Scott, 1996, p. 172). En la Odisea, tenemos informe de cuatro aedos. Mientras dos son objeto de alusión, pues apenas conocemos algo de su actuación, alcanzamos a contemplar en plena acción a otros dos. El primer par se asocia con los hijos de Atreo, Agamenón y Menelao, es decir, con quienes fungen de soberanos en los reinos de Micenas y Esparta, respectivamente. De ninguno de ellos Homero nos ofrece su nombre, esa primera seña de identidad de cualquier agente humano. Y sin nombre, parlante o no (de uso frecuente entre los griegos e incluso en muchas otras culturas), resulta difícil trazar las líneas de una genealogía. Preguntar por los padres, en un mundo donde el otro desconocido encarna tanto la condición de extranjería como la posibilidad de ser un enemigo en potencia, es más que una simple fórmula de cortesía; dicha pregunta significa, antes bien, una especie de carta forzada para conceder o no a alguien la hospitalidad (Edwards, 1975, p. 54; Iriarte, 2007, pp. 197 y ss; Santiago Álvarez, 2004, p. 26). La xenia, como institución sagrada que cuenta con el aval inviolable de Zeus, se extiende a lo largo de generaciones y se actualiza simbólica y materialmente cuando dos o más individuos, que no se conocen, intercambian palabras amistosas y hacen evidentes sus respectivos linajes (cf. Homero, 2007, VI, pp. 145 y ss.; Homero, 2000, III, pp. 80 y ss.; IV, pp. 137 y ss.). Únicamente descubriendo antiguas alianzas de acogida, el residente puede convertir en huésped al recién llegado. Este es uno de los modos (pues el otro es la fijación de parentescos por matrimonio) como los nobles homéricos amplían el alcance de sus redes políticas. Hospedaje, con una contraprestación de servicios atípica, pero sin hacer mención de ninguna otra clase de alianza (en el sentido mencionado), es el vínculo que parece mediar entre el aedo de Micenas y Agamenón. Por boca de Néstor, y situando lo contado veinte años atrás, Telémaco se entera de que a) el rey, antes de partir a Troya, deposita en un aedo el cuidado de su esposa Clitemnestra, y de que b) dicho aedo es asesinado por Egisto, sobrino de aquél (Homero, 2000, III, 266-272). La irregularidad del hecho deriva de una significación que brota por contraste: en ninguna otra parte del poema se nos revela que sea función de un aedo velar por la seguridad de alguien (incluso si esta persona es tributaria de dignidad real), y, en cambio, en los demás pasajes se nos hace saber que su tarea guarda relación con los encuentros festivos humanos; encuentros de enlace matrimonial, por ejemplo, donde vemos intervenir al aedo de Esparta (Homero, 2000, IV, pp. 17-19).

El segundo par de aedos, de entrada, enseña una diferencia notable respecto del primero: portan nombres propios que, al tiempo, hacen latir vetas de sentido tácitas (aunque quizás conocidas por los auditorios griegos primarios). Así, Homero llama Femio al aedo de Îtaca, y en dicho nombre laten las ideas de lo rumoroso, "el decir que pasa de boca en boca" e incluso "lo afamado"; y denomina 
Demódoco al aedo que habita en la isla de los feacios, en cuya designación parece resonar la idea de "aquel que es reconocido por el pueblo" o "el que es acogido por la comunidad” (Nagy, 1999, pp. 17-18). Adicionalmente, otra diferencia, que sobrepasa la inscripción nominativa, salta a la vista en lo que respecta a Femio y Demódoco: allí donde son convocados por Homero, en medio de reuniones de hombres, siempre los vemos como personajes activos y, más, actuantes. Cierto que del primer par de aedos cabe presumir que también actúan (uno, el de Micenas, en el interior del palacio y ante un auditorio singular -el constituido por Clitemnestra-, y el otro, el de Esparta, "bajo los altos techos de la excelsa mansión" y ante un público compuesto de muchos parientes); pero nunca sus respectivas actuaciones se trasuntan en líneas verbales, reproducidas en estilo directo, a la manera como se transparenta, en términos rítmico-melódicos, la performance de Femio, al comienzo y final del poema, y la de Demódoco, en la parte central de la obra.

A despecho de las diferencias señaladas, una nota, de índole sociológica, es común a los cuatro aedos homéricos: no habitan en casas propias sino en casa ajenas, y, sobre todo, en asentamientos palaciegos. Como auténticos centros de poder, que reúnen en la figura del monarca las funciones básicas de cualquier organización comunitaria, los palacios proclaman, con sus amplias salas y sus lujosos materiales de construcción, la eminente dignidad de la autoridad real (Vernant, 2008 [2004], p. 135). En contraste con otras moradas, tales mansiones tienen valor de clase, $y$, por consiguiente, son parte de la propiedad del estamento de los aristócratas. Solo que el gobierno doméstico, además del espacio físico, incluye personas e instrumentos, sean estos inanimados, sean animados, como los esclavos (cf. Aristóteles, Política, I, 1253b, 4,2). Por encima de los esclavos, y bajo los señores, ocupando una posición intermedia, la casa aristocrática aloja un amplio grupo de individuos "para el cual no hay más palabra que una designación colectiva: multitud” (Finley, 2014 [1954], p. 68). Pronto, quienes conforman esta masa de individuos comienzan a desmarcarse, por así decirlo, según la labor que realizan: aquí está el copero, allí la nodriza, allá el heraldo y, más allá, por citar unos cuantos oficios, los que, resguardados en toscas cabañas (caso del porquero Eumeo), cuidan el ganado de su amo. Diríase que los aedos, al no ser esclavos ni descendientes de nobles hereditarios -como ocurre con el grupo de los pretendientes de Penélope- se sitúan al mismo nivel de aquellos que obran como funcionarios de palacio. Mientras pervive el lazo social que los vincula a la clase señorial, están compelidos, sin más beneficios que los que proceden del alojamiento como tal, a realizar también una función especializada.

Conviene, con todo, matizar lo dicho. Admitir que los aedos se ubican dentro del grupo de los funcionarios de palacio no implica forzosamente que se los deba asimilar a ellos, alegando un principio de igualdad funcional. Dos razones se oponen a esta eventual asimilación. Primera: si las gentes (que antes llamamos -con Finley- multitud) colaboran en el empeño de que el engranaje administrativo no deje traslucir el menor atisbo de caos interno, y de ahí la necesidad de que se apliquen a cumplir con unas tareas que están encauzadas a satisfacer esencialmente las necesidades primarias de la vida (alimentación y vestido, entre ellas), los aedos se ponen al margen de toda esta multiforme actividad doméstica, limitándose a intervenir exclusivamente cuando los hombres eminentes, en presencia o no de sus esposas, así se los demandan, al menos durante la ocasión social llamada banquete. Segunda: de algunos servidores de palacio se puede afirmar, encareciendo el juicio, que son depositarios de ciertos rasgos exclusivos, hasta el punto de que personifican el paradigma de las más relevantes virtudes éticas (sentido de justicia y templanza, como exhibe la conducta de Eumeo; discreción y lealtad, como muestra el comportamiento de Euriclea; o prudencia y sensatez, como deja traslucir la actitud de Filetio); pero de pocos, y con una fuerza y un valor de sentido que sobrepasa el recurso de la exposición formularia (presente, por ejemplo, en Homero, 2000, XIV, p. 48, o XIV, p. 413), se pondera el epíteto con que invariablemente Homero caracteriza la identidad de los aedos: divinos (theios) (I, p. 336; IV, p. 17; VIII, p. 44; IX, p. 2; XVII, p. 385; XX, p. 347; XXII, p. 347; xxIII, p. 133). Con ser que no parece haber palabra en Homero que no obedezca a las coacciones de 
una estructura métrica regular, la iteración de este adjetivo, usado para enaltecer la figura de los aedos, no resulta insustancial.

Antes de que la escritura se convierta en instrumento de comunicación al alcance de muchos, un acontecimiento que algunos estudiosos, siguiendo a Heródoto $(2008,5,58)$, han datado entre finales del siglo Ix y comienzos del viII a.C. (Latacz, 2003 [2001], p. 212; Wood, 2013 [1985], p. 162; Martínez García, 2015, p. 104-105), la memoria es el soporte al que apelan los griegos para conservar y trasmitir su propia tradición. Memoria, aquí, recubre dos sentidos: técnico y religioso. Técnico, puesto que se trata de desarrollar una serie de mecanismos de repetición tendientes a resguardar, dentro de un vasto espacio de variaciones, los bienes culturales de la comunidad. Sin el cultivo de una compleja tecnología evocativa, lo conocido corre el riesgo de perderse definitivamente (Ong, 1994 [1982], p. 32). Y religioso, puesto que los griegos homéricos, tan proclives a pensar por imágenes, pues no en vano para ellos la poesía es sentimiento o idea hecha imagen (Havelock, 2002 [1963], p. 21), dotan a la memoria de una suerte de revestimiento divino. Sacralizada por la mentalidad griega, hasta el punto de hacer de ella la fuente por antonomasia de la inspiración poética, esta memoria se concibe como algo diferente de la simple facultad psicológica que poseen todos los hombres. En palabras de Detienne, "es una omnisciencia de carácter adivinatorio, y por eso se define, a semejanza del saber mántico, con una fórmula: 'lo que es, lo que será y lo que fue"' (2004 [1967], p. 62; Homero, 2007, I, p. 70; Hesíodo, 2006, pp. 32 y 38). Esta memoria es una suerte de potencia religiosa que atraviesa la apariencia fenoménica de las cosas, descubre la esencia de los eventos y acontecimientos y hace ver lo que los demás no ven. Pero, ante todo, ella es una dación sobrenatural que recae, trasfigurada por las Musas, hijas de Mnemosyne (la memoria), en los aedos. En cuanto productores de epifanías que originan a la vez el asombro y el deleite, dichos cantores, mediante la memoria, "instituyen por virtud propia un mundo simbólico-religioso que es lo real mismo" (Detienne, 2004 [1967], p. 62).
No otra cosa es lo que proclama Hesíodo en su Teogonía: "De las Musas y del flechador Apolo descienden los aedos y citaristas que hay sobre la tierra; y de Zeus, los reyes. ¡Dichoso aquel de quien se prenden las Musas! Dulce le brota la voz de la boca" (2006, pp. 95 y ss.). Dulce es el canto de Demódoco, a quien la Musa, según Homero, le otorgó, a cambió de su ceguera, el venerable don del canto (Homero, 2000, vIII, pp. 62-64). Así, soportado en una memoria que sabe preservar motivos y palabras de un determinado grupo social, y asistido por Calíope, la musa que aglutina en torno suyo las funciones que se requieren para el desempeño poético general, el aedo se erige, en el marco de las comunidades analfabetas, como un personaje venerable. Si recibe de los hombres (de los nobles, en particular) una valoración excelsa, un trato preferencial, no es solo porque exhiba un saber técnico que pone al servicio de los demás (pues si esto bastara, en nada se diferenciaría de los otros servidores de palacio), sino porque en las narraciones que canta, en los relatos que entona, un individuo -pero sobre todo una comunidad- se puede autocontemplar en sus rasgos más significativos, esto es, en sus creencias religiosas, gestas fundacionales, actividades de producción, valores morales, convenciones sociales, etc. (Havelock, 2002 [1963], p. 59 y ss).

\section{¿Qué podemos decir de la actividad de los aedos?}

Como atrás insinuábamos, el aedo es un cantor de canciones, o, también, entonar canciones es el tipo de actividad que caracteriza al aedo ${ }^{1}$. Todo

1 Si los dioses y héroes se revelan a través del habla, los aedos se revelan a través del canto. Antes de examinar el registro de los aedos, describamos unos cuantos aspectos de lo que podría denominarse el habla heroica. Para empezar, los héroes, además de combatientes, en el sentido de que se juegan su existencia en la guerra, y algunos, como Odiseo, en una serie de aventuras que ponen constantemente a prueba su ingenio, son también, y con mucho, oradores (Homero, 2007, XII, p. 443). Ser batallador supone tomar parte en el combate, o en su defecto, en alguna andanza temeraria; ser orador, por su parte, implica participar en las resoluciones del consejo o de la asamblea. La pica o lanza de guerra es a la lucha bélica, lo que el discurso público es al encuentro deliberativo entre iguales, es decir, entre reyes. Aun cuando no es lo acostumbrado, sucede a veces que una asamblea se desarrolle como si se tratara de un enfrentamiento armado (piénsese en la disputa entre Aquiles y Agamenón), y que un inminente duelo entre dos combatientes se sazone previamente con largos discursos 
canto implica la oralidad, pero esta no se restringe al canto. En cuanto manifestación oral, el canto, para los griegos, constituye una forma específica de imitación: la que se hace, no con colores y figuras, sino con la voz (Aristóteles, 1988, 1, 1447a, 19-26). Y más: en la medida en que el canto es palabra sometida a un patrón melódico menos natural que artificial, el aedo deviene artífice de cantos. En una de sus dimensiones, el artificio "consiste en trabajar, según un plan no natural, ese material natural que se denomina aire ... y en hacer trabajar, según un plan, que no es el natural fisiológico, a ciertos órganos del cuerpo humano" (García Bacca, 1985, p. 21). Los órganos trabajan con el fin de hacer audible una articulación que se adecúe a los metros que han sido establecidos por convención. El metro fija la medida articulatoria de la emisión oral y regula la dicción del canto. Articulación, entonación y dicción son todos procesos artificiales que el aedo debe dominar tras largos años de entrenamiento.

Sumado al talante natural, la labor del aedo se asentaría en un aprendizaje, de carácter autoinstruido o no (pues el aedo de Ítaca se jacta de haberse educado por cuenta propia), cimentado en el dominio técnico de la voz y la experiencia. Pero existe otro aprendizaje, complementario del primero, cuyo objeto trasciende los aspectos que conciernen a la modulación verbal. Dicho aprendizaje versaría, no sobre la apropiación de canciones ya existentes (aunque no conviene descartar de plano esta posibilidad), sino sobre los diversos modos de ensamblar los motivos con que las canciones son elaboradas. A juzgar por los cantos que entonan Femio y Demódoco,

como los que se profieren en una justa oratoria (piénsese en la disputa en Glauco y Diomedes). Además, si el desempeño individual en la batalla responde a un código heroico que contempla la posibilidad de hacerse con las armas del vencido, la actuación oratoria entraña la finalidad de persuadir al otro apuntalándose en el uso de argumentos convincentes que tocan por igual el corazón y la mente del interlocutor. De ahí que el refinamiento retórico en el dominio de la palabra -escribe Jaeger- signifique, respecto del comportamiento heroico, "una sabiduría del espíritu" (1967, p. 24). Por último, la acción heroica, al consumarse, y tanto mejor si la consumación acarrea la muerte de un número abultado de enemigos, tiene la opción de convertirse en rumor afamado, tal como este, al cantarse, puede instigar, por emulación, nuevas gestas o hazañas caballerescas en quienes superan la pubertad y están a punto de convertirse en hombres adultos. y los cuales son reproducidos por Homero conforme a un procedimiento de fusión discusiva que integra en una sola unidad mimética tanto los versos de estos cantores cuanto las tiradas que son atribuibles al narrador dominante del poema, tales motivos no son otros que los que configuran cualquier relato: personajes, episodios, intrigas, descripciones de espacios, acciones, etc. Plasmados en expresiones fijas o fórmulas, término acuñado por Parry (1971) para nombrar el método inherente a la composición oral, los motivos mencionados constituirían los cimientos -incluso, los sedimentos esenciales- de toda canción posible. Retener en la memoria estos motivos, ensayar combinaciones creíbles (pero no exentas de atributos sorprendentes o maravillosos), articular esas combinaciones en conjuntos mayores dotados de cohesión diegética o dramática, serían algunos de los procesos mentales y artísticos en los cuales se afianzaría el oficio de los antiguos cantores. Tras largas jornadas de aprendizaje, "los aedos dispondrían de un ingente depósito de materiales (motivos y fórmulas) y con ellos edificarían sus obras" (Finley, 2014 [1954], p. 37). Edificar, en este contexto, significa improvisar, repentizar (Carlier, 2005 [1999], p. 51). Y como improvisar es un tipo de ejecución artística que se realiza en el acto, directa e inmediatamente ante un auditorio, la canción resultante devendría siempre única y nueva, al no contarse para entonces con un sistema de fijación escrita que la salve del olvido (Dalby, 2008 [2005], p. 56).

Aunque Homero no describe físicamente a ninguno de los cuatro aedos que menciona, sí indica un objeto que ayuda a identificarlos. Del mismo modo que en la épica no cabe hablar de guerreros sin armas, de reyes sin cetros o de adivinos sin bastones, así no es posible imaginar a los cantores sin fórminges, cítaras o liras, todos instrumentos de cuerda. De los tres, la lira - ¿de seis cuerdas?- y la cítara, simple o de cuna, la primera de cinco cuerdas y la segunda de cuatro, son atribuidas a Demódoco, a Femio y al aedo de Esparta, respectivamente (Espejo Muriel, 1991, p. 168). La fórminge aparece citada en la Ilíada, y su manipulación corre a cargo del mejor de los aqueos, Aquiles (IX, p. 186). Sonora es el adjetivo-fórmula empleado por Homero para 
calificar cualquiera de estos instrumentos. Tomar en las manos la lira o la cítara es indicio inequívoco de que el aedo va a comenzar a cantar, acción paralela al hecho de que recibir de las manos del heraldo el cetro es signo evidente de que alguno de los principales argivos va a hacer uso de la palabra. Así, la lira o cítara es al canto lo que el cetro (skeptron) es al habla de autoridad. Ambos son, pues, objetos impregnados de valor simbólico, o, si se prefiere, emblemático. El acto de rasgar las cuerdas es simultáneo al de cantar, lo mismo que el de apretar el cetro es concurrente al de discursear. La actividad culmina, o se interrumpe, cuando el aedo deja de tañer su instrumento o cuando el hablante devuelve el cetro al heraldo o lo arroja abruptamente al suelo (como hace Aquiles después de disputar agriamente con Agamenón, al principio de la Ilíada). Dejando de lado otras analogías que pueden ser acotadas, digamos que, respecto del aedo, la mano que pulsa las cuerdas y la voz que articula los cantos a base de expresiones formularias se aparejan de un modo indisociable para llevar a cabo la ejecución oral. ¿Qué vincula al aedo con su público? Sin duda, una experiencia audio-táctil, inherente a toda sociedad ágrafa. Lo que menos importa en esta experiencia es la visión (la capacidad de mirar); lo que importa, realmente, es el efecto emotivo que suscita en el auditorio. $Y$ este efecto procede al mismo tiempo de la estructura rítmica del canto que es acompañado por los acordes del instrumento musical y de las acciones referidas mediante la modalidad de la imitación diegética.

Adicionalmente en la Odisea, aparte de cantos interpretados con el auxilio de un instrumento de cuerdas, se describe otra actividad que se desprende de la función característica de los aedos. Esta actividad es la danza. Homero no afirma, ni siquiera sugiere tímidamente, que sea deber u obligación de los aedos encargarse de organizar el baile que, a veces, sucede al canto; pero sí declara que, en Esparta, al compás del canto interpretado por el aedo, "dos saltadores danzaban ... y saltaban en medio de todos" (IV, pp. 18-19) y que, en la isla Esqueria, patria de los feacios, "los mancebos floridos más diestros en todas las danzas" (viII, 263), golpean con los pies la liza, mientras Demódoco, ubicado en el centro, toma la lira que le pasa el heraldo y se prepara para cantar "los amores de Ares y Afrodita". Desde luego estamos ante dos circunstancias diferentes y opuestas entre sí: en la primera, el baile se nos ofrece como si fuera una continuación por otros medios del contenido del canto (contenido silenciado, aun cuando quizás relacionado con el contexto epitalámico que rodea a los miembros de la familia real); en la segunda, la danza se nos revela como una especie de preludio al canto que viene a continuación y cuyo tema Homero explicita y compendia antes de que el aedo proceda a recrear una graciosa historia de adulterio entre dioses. En cualquier caso, la evidencia textual a duras penas arroja luz sobre un posible condicionamiento recíproco entre las artes de cantar y danzar. Y suponiendo que lo hubiera, el nexo estaría dado, menos por la opinión de que ambas manifestaciones son el condimento de todo banquete (Homero, 2000, XVII, pp. 271, 359, 385) que por los tipos de canto en que pueden ser agrupadas las intervenciones de los aedos.

¿De qué hablan, o, mejor, cantan, los aedos? (Sobre algo). Y, ¿a quiénes van dirigidos sus cantos? (Auditorio)

Los cantos que son objeto de alusión, y que en la Odisea corresponden básicamente a los motivos del duelo-Xxiv, p. 60-y de bodas-IV, p. 17; XxIII, p. 134-, pueden catalogarse, según la distinción que propone Redfield, como "cantos para algo" (2012 [1994], p. 64). Homero no ofrece detalle alguno sobre la forma y el contenido de estos cantos. Lo que sea que incluyan, en términos temáticos (¿rogativas lastimeras?, ¿deseos de felicidad?) y formales (¿un metro homogéneo?, ¿una textura melódica mixta basada en la combinación de dos o más secuencias rítmicas diferentes?), aparece elidido. En lugar de ello, el texto nos induce a inferir: es el hecho social el que determina el canto, no al revés. El canto varía conforme a la naturaleza del hecho social descrito. Y más: el hecho, una vez es cualificado por el canto, origina, entre los asistentes, una actividad correlativa. Merced al canto de duelo, los asistentes responden con un llanto colectivo; y gracias al canto de bodas, 
algunos circunstantes prolongan el canto con danzas y saltos. Más que acompañar la ceremonia, el canto invita a participar en ella, convirtiendo a los asistentes en concelebrantes. No es que el canto no sea escuchado; es que la escucha trasciende el acto de la producción verbal y se consuma bajo la forma de una respuesta corporal. De esa manera, el canto del aedo, antes que dar cuenta de una actuación individual, engrandecida artísticamente por el uso de la lira o la cítara, testimonia una experiencia grupal cuya finalidad es reafirmar el sentimiento de pertenencia a una misma comunidad. Al ser una función de circunstancia, el canto para algo y la respuesta que mejor se adecua a él conforman una práctica cultural regulada por géneros (pues Homero, si no en la Odisea, deja saber, en la Ilíada, que existen otros cantos igualmente sancionados por una ocasión social, por ejemplo, cantos de vendimia - XVIII, 567 y ss.-, o de victoria-XXII, p. 31-). Si a Homero le basta con insinuar estas canciones, quizás sea porque se mantienen "a lo largo de la historia... como un telón de fondo y una reserva" en los que no es necesario ahondar (Redfield, 2012 [1994], p. 64).

Homero trasciende el registro de la mera alusión y abre un espacio épico para informar de la existencia de otros cantos que no tienen que ver con hechos de muerte ni con episodios de esponsales. Redfield los inscribe en una segunda clase a la cual da el nombre de cantos por el canto (2012 [1994], p. 64). En general, son los cantos que entonan, en locaciones diferentes, Femio y Demódoco. Considerados en bloque, muestran las siguientes particularidades: a) dado el procedimiento de fusión discursiva del que antes hablamos, y cuya eficacia se basa en que dos voces (la de Homero y la del cantor) se oyen -o leen- como si fueran una sola, los cantos se ensamblan en hexámetros regulares, ajustándose al esquema formal de las tiradas de versos y afincándose en el uso de palabras o frases formularias; b) invariablemente, la ejecución de estos cantos, como también ocurre con los cantos de duelo y de bodas, no se concibe sin el acompañamiento instrumental de una lira o una cítara cuya interpretación es también tarea de los cantores; c) aun cuando no obedecen a una circunstancia específica, o no están determinados por una ocasión social concreta, los cantos se interpretan en el marco de una situación definida: la que mueve predominantemente a los hombres, pues nada impide que una mujer esté presente (como es el caso de la reina Areta, entre los feacios), a reunirse en el amplio salón de la residencia real (megaron); d) los cantos narran, o celebran, según la expresión usada por Hesíodo (2006, pp. 100-101) historias de los inmortales y gestas de hombres (gestas signadas, de una parte, por el carácter glorioso de la acción, pues se presume que cuentan con el favor y la gracia de alguna divinidad, $y$, de otra, coronadas de fama, una fama que, las más de las veces, se pondera hiperbólicamente, como quiera que de ella se predica "que llega hasta el cielo"; y e), por último, los cantos llegan a ser siempre nuevos, dado que son el resultado, no de una preparación previa, sino de una improvisación a viva voz que echa mano de una serie de motivos sedimentados por la tradición (Dalby, 2008 [2005], p. 28).

¿Por ventura este segundo tipo de cantos se cierra sobre sí mismo, sin desempeñar más función que la de proporcionar un deleite sobrecogedor, como parece insinuarlo el nombre utilizado por Redfield? No lo creemos. Tales cantos, al vehicular un mensaje cuyos agentes principales son héroes y dioses, es decir, hombres tocados por la divinidad y seres que se mezclan con los mortales, incluso sexualmente (Vernant, 1991 [1990], p. 41), son testimonio de una visión del mundo que reproduce, por la vía indirecta del arte poético, uno de los aspectos más relevantes de la organización palatina griega: el de la justificación de la soberanía misma (Detienne, 2004 [1967], p. 63). Efectivamente, en la Odisea, la veta narrativa que describe el retorno del héroe Odiseo halla su más hondo sentido en la veta diegética que describe el vacío de poder que, durante veinte años, ha dominado a Ítaca. Por eso la ambición de los pretendientes es hacerse con la mano de aquella mujer -Penélope- cuya aquiescencia matrimonial podría poner fin a dicho vacío de poder. Si Odiseo satisface la condición de héroe, no es solo porque exhiba unas cualidades físicas e intelectuales que superan con mucho las características de un 
mortal ordinario, sino porque sus atributos se asocian estrechamente con el señorío, la nobleza. En cuanto señores, los héroes homéricos, y especialmente Odiseo, personaje dominante en los cantos de Femio y Demódoco (si exceptuamos la canción que este último entona a propósito de los amores ilícitos entre Ares y Afrodita), se ven en la obligación de responder a una doble exigencia vital: orientar incesantemente sus virtudes en procura de alcanzar la supremacía entre sus pares, pues incluso durante los periodos de paz debe probar que su arete se mantiene (Jaeger, 1967, p. 63) y defender el señorío contra cualquier clase de intrusión o exacción (acción que define los designios de los pretendientes). Tales cantos, entonces, constituyen un recordatorio de cuán frágil es la soberanía, y de cuán azarosa es la existencia de los héroes, en el seno de un ambiente natural donde las potencias divinas a menudo tienden a ser confundidas con el destino fatal (Østerud, 1976, p. 76).

Ahora bien, volquemos la atención sobre el público, el otro aspecto de esta tercera parte de la conjetura. Para el oyente -o lector- pronto resulta claro que Femio y Demódoco actúan ante auditorios diferentes. Las diferencias rayan en la oposición. En principio, Ítaca y la isla Esqueria, espacios donde aquellos ejecutan respectivamente su arte, constituyen asentamientos humanos marcados por la oposición realidad/irrealidad. Según Vidal-Naquet,

[...] el texto mismo proporciona la prueba de que esta oposición es correctísima. El viaje de Telémaco nunca coincide con el de Ulises. Solo existen dos zonas de contacto entre los dos universos: una, abiertamente, mágica, en la que Menelao revela al hijo de Ulises que en la tierra de las maravillas -Egipto- se ha enterado por el mago Proteo de que Ulises está junto a Calipso y es retenido por ella; la otra, la tierra de los feacios [...]. Los viajes de Ulises no conciernen a la geografía, pero hay una verdad geográfica mucho mayor en los relatos 'mentirosos' de Ulises a Eumeo y a Penélope que en el conjunto de relatos ante Alcinoo. Tanto Creta, Egipto como Epiro tienen una 'realidad' que nadie pondrá en duda" (1983 [1981], pp. 39-40).
Después, los escuchas que concurren en ambos espacios son mayoritarios en un caso (Ítaca) y minoritarios en el otro (isla Esqueria). Mayoritarios son los pretendientes, cuyo número, 108, informa con precisión Telémaco a Odiseo, cuando se produce el recíproco reconocimiento (anagnórisis) entre hijo y padre: "De Duliquio han venido cincuenta y dos jóvenes [...], veinticuatro mancebos ilustres vinieron de Same y veinte más de Zacinto [...] y de Ítaca otros doce que son los más nobles de todos" (Homero, 2000, XVI, pp. 247-251); minoritarios, en comparación con los pretendientes, son los feacios (reyes y cortesanos), y singular es el huésped acogido por ellos: Odiseo. Y, por último, la situación de Femio y Demódoco es cualitativamente contraria: mientras el cantor de los feacios goza de plena libertad al momento de elegir los cantos (lo cual no implica que uno de los miembros del auditorio no pueda solicitarle que interprete alguna canción en especial), el cantor de Ítaca disfruta de una libertad atada (el oxímoron es inevitable), pues en dos ocasiones, al comienzo y final del poema (Homero, 2000, I, p. 154 y xxII, p. 353), Homero revela que Femio canta muy a pesar de su deseo, bajo la coacción ejercida por los pretendientes.

En la isla Esqueria, la posición de Odiseo es inversa y simétrica respecto de la de Penélope. Inversa, en el sentido de que el héroe es uno en medio de un grupo cerrado (los feacios), mientras que en Ítaca un grupo cerrado (los pretendientes) intenta conseguir el voto matrimonial de Penélope. Y simétrica, puesto que dos de los tres cantos que Demódoco interpreta causan en Odiseo, quien hasta ese momento no ha revelado su identidad a los feacios, la misma respuesta demostrada por Penélope al oír la canción de Femio: una tristeza acrecida por el llanto (Homero, 2000, viII, pp. 92, 522). Si el héroe moja las mejillas en presencia de gentes nobles y hospitalarias, no es porque Demódoco refiera hechos infaustos o desventurados. Basta reparar en los motivos de la primera y tercera canción para corroborar lo dicho. El llanto, como reflejo auditivo, obedece a un par de razones, épicoliteraria, una, y cultural, la otra. Épico-literaria entraña mostración de un sentimiento probable en 
quien que, tras años de aventuras y padecimientos, oye cantar a alguien -que no tomó parte en la expedición a Troya y no tuvo conocimiento personal de las miserias de la guerra- el relato de sus propias hazañas. Para Odiseo, los cantos de Demódoco representan una actualización de sus recuerdos, remozados verbalmente gracias al recurso de una palabra ajena. Y cultural, ya que Odiseo descubre que sus gestas no han caído en el olvido y se han hecho merecedoras de fama; una fama a todas luces especial, no tanto porque sea inmerecida o producto de una atribución sustentada en el engaño (asunto que Sófocles aprovechará para componer su Áyax), cuanto porque le es otorgada a quien todavía no ha muerto, o mejor, a quien aún no ha traspasado los límites de la vida. Se trata, por lo demás, de una fama precoz o adelantada, si pensamos en que es el propio héroe el que solicita al aedo que cante, en la forma debida (Homero, 2000, viII, p. 496), el episodio del caballo de Troya en el que él actuó como protagonista. Y para cuando Odiseo arriba a la tierra feacia solo han transcurrido diez años desde que los aqueos vencieran la resistencia de los troyanos. Es decir que una década ha sido suficiente, si seguimos la lógica de los acontecimientos mencionados por la leyenda nacional griega (un todo integrado por los poemas homéricos y los denominados poemas del ciclo troyano) para que el nombre del héroe se haya convertido en materia de canto.

Hay una cuarta oposición, sin duda más importante que las anteriores: la que concierne a la relación entre el tipo de canción entonada por los aedos y la respuesta emocional del auditorio. En Ítaca, Femio interpreta una canción que habla del aciago retorno de los aqueos. Atrás ya comentábamos que Homero veló su contenido; luego, lo que tenemos es básicamente el tema. De inmediato, Penélope, en su alcoba, situada en la segunda planta de la casa, baja por la escalera, acompañada de dos esclavas, y, una vez llega ante la masa de pretendientes, deja caer el velo que cubre su rostro y se dirige a Femio con el fin de que, a cambio del canto que ejecuta, module otro más grato y menos triste. ¿Qué ha ocurrido? Que Penélope, sin ser integrante del auditorio, ha obrado como testigo de audición. La intervención de la reina, sin ser atípica, resulta anómala. La anomalía no depende de una presunta prohibición de escuchar; depende, antes bien, de una transgresión de roles, pues la convención establece que el uso de la palabra, ora bajo la forma del canto, ora bajo la del habla, es privativo de los hombres y solo de ellos (Homero, 2000, I, pp. 358-359). Por contraste, los pretendientes, en cuanto auditorio general, permanecen en silencio. Mal haríamos en comprender dicho silencio como ausencia de respuesta emocional. Este silencio dice más de lo que calla, pues conviene a los intereses de los pretendientes que un aqueo en particular, de los miles que emprendieron el viaje hasta Troya, nunca regrese: Odiseo. En otras palabras, la reina, al margen del auditorio, pone al descubierto lo que los pretendientes, como bloque, escamotean al oír el canto del aedo: su propia reacción sentimental. Y dado que la canción de Femio parece ser siempre la misma, pese a que él dice haber aprendido toda clase de cantos (Homero, 2000, XxII, p. 349), y a que Telémaco no ignora que "los hombres prefieren brindar sus elogios a los más nuevos cantos que pueden llegar a su oído" (Homero, 2000, I, pp. 351-352), los pretendientes hacen del silencio un signo de alegría bien disimulada.

Únicamente un canto, de entre todos los que Homero atribuye a los aedos de Ítaca y la isla Esqueria, provoca en el auditorio una inmediata y gozosa respuesta de complacencia: el que, con moroso cuidado, Demódoco dedica al tema del adulterio divino. La canción -opina Redfield- "es de tono alegre y resalta las divertidas bromas que se hacen unos dioses a otros (2012 [1994], p. 64). Odiseo y los hombres feacios se regocijan por igual al escucharla. El júbilo que produce este canto incita a Alcínoo a ensalzar el espíritu festivo del encuentro. De suerte que ordena a Helios y Laodamao, los dos más conspicuos danzarines feacios, a que hagan ostentación de su arte ante Odiseo. Lo que sigue, el baile con una pelota (Homero, 2000, viII, pp. 370380 ), es quizás el primer testimonio literario en Occidente de una coreografía lúdica. Y sirve de ilustración, con mucho, de aquello que constituye, si no la esencia, la gala del banquete homérico, a saber: el canto y la danza (Homero, 2000, I, p. 152), 
acoplados en jovial armonía. Por enumeración contextual, más que por una meticulosa descripción, Homero nos pone al tanto de la auténtica función que ha de cumplir el aedo: adobar los encuentros palaciegos, no con cánticos tristes (como los que Femio se ve forzado a entonar por mandato de los pretendientes), sino con cantos alegres, como los que Demódoco, inspirado por la Musa o por el mismo Apolo (Homero, 2000, vilı, p. 488), interpreta para Odiseo y sus anfitriones. En apoyo de esta idea, leemos en el poema la invitación que Alcínoo hace a los feacios destinada a solicitar el cese del canto del aedo, cuando descubre que su huésped, sentado a su lado, no para de sollozar al reparar en lo que oye (Odisea, VIII, 535-541).

\section{Conclusiones}

Es lícito afirmar que, al leer a Homero, y puntualmente la Odisea, nos situamos, desde cierta perspectiva, en los albores de lo que Occidente hoy entiende por literatura, así esté fuera de duda que este poema, junto con la Ilíada, como insignes exponentes de la poesía oral, representen la culminación de un dilatado pasado, al tiempo ensombrecido y clareado por siglos de actividad artística verbal. Uno de los rasgos de esta poesía, "que se compone y trasmite sin ayuda de guiones y apuntes anotados en cuadernos [...] y que se aprende y elabora auditivamente, mediante el oído" (Kirk, 1985, p. 69), consiste en la inclusión de numerosos personajes, algunos de los cuales apenas si desempeñan una función precisa y otros, en cambio, una función sustantiva.

De estos últimos, existe uno en particular que en la Odisea realiza una labor privativa de unos pocos: cantar. Aedo es el nombre de este personaje cantor y las odas (canciones) son el producto de su actividad. Usualmente, lo vemos realizando su labor en el seno de casas aristocráticas, muy a menudo ocupadas por individuos que se precian de un linaje divino y por un ámbito de acción ligado a la guerra. A diferencia de otros funcionarios del palacio, que empeñan su fuerza de trabajo en el mantenimiento ordenado de la administración doméstica, el aedo ejecuta una actividad menos material que espiritual, por no llamarla cultural.

Dicho sujeto, siempre venerado por los circunstantes que demandan el ejercicio de su labor, sustenta su arte en la tenencia de una memoria excepcional, cuyo entrenamiento pasa por el aprendizaje de cientos de motivos y expresiones reiteradas (el llamado estilo formulario), y en el acompañamiento de un instrumento musical de cuerda (la lira o la citara, preferentemente). El canto del aedo, lejos de estar pautado por un guion específico, se abre a varias manifestaciones poéticas que pueden ser agrupadas en dos clases: cantos de ocasión y cantos de gestas. Respecto de los primeros, los llamamos cantos de ocasión, o de circunstancia social, ya que es esta la que determina el acto de cantar y el tipo de canciones, pero no lo contario. El fin de esta clase de cantos (himeneos, epinicios, endechas, etc.) es fortalecer el vínculo social de una comunidad autenticando prácticas colectivas tradicionales. Respecto de los segundos, los cantos cumplen la función de refrendar la estructura social aristocrática, en la que los aristoi -los mejores, en el doble sentido físico y espiritual- no solo ocupan el poder, sino también que lo refirman mediante relatos de acciones eminentes, esforzadas y afamadas, de los cuales forman parte alusiones o referencias directas a las divinidades. El aedo, al interpretar cantos que remiten bien a prácticas rituales, bien a leyendas divinas y heroicas, funge de intermediario en una sociedad jerárquicamente dividida, en la que gentes del común y nobles guerreros o viajeros coexisten de modo complementario.

Estos últimos, al constituirse en auditorio, responden al canto exhibiendo un silencio respetuoso y distante (como prueba del estatus que se concede a este funcionario de palacio) o manifestando una emoción de alegría o llanto. Aunque las dos respuestas emotivas son posibles, lo que el auditorio espera del aedo es que avive el tiempo de los encuentros humanos con tonadas que, prolongándose en la danza, fortalezcan el placer comunitario (Gentili, 1984, p. 73). Dicha respuesta es el síntoma positivo con el cual el público valida y elogia al aedo como 
cumplido poeta cortesano (Brioso Sánchez, 1984, p. 137). Que la figura del aedo se alce en el poema homérico en calidad de personaje actuante, y por tanto como miembro de una corporación identificada a partir de la realización de un oficio común, según se desprende de la expresión philon aoidon (Homero, 2000, viII, p. 481), y del hecho de que en la Odisea se haga mención de dos aedos innominados y dos designados con nombre propio -Femio y Demódoco-, acaso sea un sutil indicio de que, ya desde los orígenes mismos del quehacer poético, la literatura, aparte de crear mundos posibles, nunca ha dejado de referirse a ella misma.

\section{Referencias}

Adkins, A.W.H. (1972). Homeric Gods and the Values of Homeric Society. The Journal of Hellenic Studies, 92, 1-19.

Aristóteles (1988). Política. Introducción, traducción y notas de Manuela García Valdés. Madrid: Cátedra.

Aristóteles (1999). Poética. Versión trilingüe por Valentín García Yebra. Madrid: Gredos.

Brioso Sánchez, M. (1984). El aedo en la Odisea. Estudios Clásicos, 26(87), 135-140.

Castoriadis, C. (2006). Lo que hace a Grecia. 1. De Homero a Heráclito. Seminarios 1982-1983. La creación humana II. México: Fondo de Cultura Económica.

Carlier, P. (2005 [1999]). Homero. Barcelona: Akal.

Chantraine, P. (1968). Dictionnaire étymologique de la langue grecque. Historie des mots. París: Éditions Klincksiek.

Dalby, A. (2008 [2005]). La reinvención de Homero. El misterio de los orígenes de la épica. Madrid: Gredos.

Detienne, M. (2004 [1967]). Los maestros de la verdad en la Grecia arcaica. México: Sextopiso Editorial.

Edwards, M.W. (1975). Type-escenes and Homeric Hospitality. Tapa, 105, 54-56.

Espejo Muriel, C. (1991). El aedo homérico. Florentia Iliberritana. Revista de estudios de la Antigüedad clásica, 2, 161-170.

Finkelberg, M. (1998). Timē and Aretē in Homer. The Classical Quarterly, 48(1), 14-28.

Finley, M.I. (2014 [1954]). El mundo de Odiseo. México: Fondo de Cultura Económica.
García Bacca, J.D. (1985). Introducción a la Poética. En Aristóteles, Poética (pp. 9-127). México: Bibliotheca Scriptorum Graecorum et Romanorum Mexicana.

Gentili, B. (1984). Poesia e Pubblico nella Grecia Antica Da Omero al V seculo. Roma: Sécolo.

Havelock, E.A. (2002 [1963]). Prefacio a Platón. Madrid: A. Machado Libros.

Heródoto (2008). Historia. Libros V-VI. Traducción y notas de Carlos Shrader. Madrid: Gredos.

Hesíodo (2006). Teogonía-Trabajos y días-EscudoFragmentos-Certamen. Introducción, traducción y notas de A. Pérez Jiménez y A. Martínez Díaz. Madrid: Gredos.

Homero (2000). Odisea. Introducción de Carlos García Gual y Traducción de José Manuel Pabón. Madrid: Gredos.

Homero (2007). Ilíada. Traducción, prólogo y notas de Emilio Crespo Güemes. Madrid: Gredos.

Iriarte, A. (2007). La institución de la Xenía: pactos y acogidas en la antigua Grecia. En: Gerión, vol. extra (25), 197-206. Universidad Complutense de Madrid.

Jeager, W. (1967). Paideia. Los ideales de la cultura griega. México: Fondo de Cultura Económica.

Kirk, G.S. (1985). Los poemas de Homero. Barcelona: Paidós Studio.

Latacz, J (2003 [2001]). Troya y Homero. Hacia la resolución de un enigma. Madrid: Destino.

Liddell, H.G. y Scott, R. (1953). Greek-English Lexicon. Oxford: Oxford University Press.

Long, A.A. (1970). Morals and Values in Homer. The Journal of Hellenic Studies, 90, 121-139.

Martínez García, O. (2015). Héroes que miran a los ojos de los dioses. Madrid: EDAF.

Nagy, G. (1999). The Best of the Achaeans. Concepts of the Hero in Archaic Greek Poetry. EE. UU.: John Hopkins University Press.

Ong, W.J. (1994 [1982]). Oralidad y escritura. Tecnologías de la palabra. Colombia: Fondo de Cultura Económica.

Østerud, S. (1976). Hamartia in Aristotle and Greek tragedy. Symbolae Osloenses: Norwegian Journal of Greek and Latin Studies, 51(1), 65-80.

Parry, M. (1971). The Historical Method in Literary Criticism. En A. Parry (ed.), The Making of Homeric Verse. The Collected Papers of Milman Parry (pp. 408-413). Oxford: Clarendon Press. 
Universidad Pedagógica Nacional

Facultad de Humanidades

Ramos, O.G. (1988). Categorías de la epopeya. Bogotá: Publicaciones del Instituto Caro y Cuervo, Series Minor, XxxI.

Redfield, J.M. (2012 [1994]). La Ilíada, naturaleza y cultura. Madrid: Gredos.

Santiago Álvarez, R.A. (2004). La familia léxica de xénos en Homero. Usos y significados II (Odisea). Faventia, 2(26), 25-42.

Vernant, J-P. (1991[1990]). Mito y religión en la Grecia antigua. Barcelona: Ariel.
Vernant, J-P. (2008 [2004]). Atravesar fronteras. Entre mito y política II. México: Fondo de Cultura Económica.

Vidal-Naquet, P. (1983 [1981]). Formas de pensamiento $y$ formas de sociedad en el mundo griego. El cazador negro. Barcelona: Península.

Wood, M. (2013 [1985]). En busca de la guerra de Troya. Barcelona: Crítica. 